\title{
The research and design of network management system of assets in schools
}

\author{
Mo Ling-lii \\ ${ }^{1}$ Wuxi Institute of Communications Technology, No.98 Qianrong Road, Wuxi, China, 214151 \\ yimi_xhc@126.com
}

Keywords: two-dimensional code technology, mobile terminal, asset management system, process analysis, function analysis, system design

\begin{abstract}
This paper, based on the analysis of the business process and characteristics of the users of school asset management system as well as the functions of asset management system, develops a suitable asset management system model through two-dimensional code technology, aiming to provide technical support for improving the level and efficiency of asset management in schools.
\end{abstract}

\section{The school asset management}

Fixed assets in schools usually consist of real estate, office furniture, teaching equipment, scientific research equipment, etc. They provide guarantees for school routines like teaching, scientific research, and administration. However, because of the large quantity and wide variety of these assets, it brings certain difficulties for asset management. Especially with the rapid expansion of colleges and universities and increased investment from our country into higher education, the scale of assets of colleges and universities gets a sharp increase. With Asset forms, quantity and structure perplexed, traditional asset management is unable to meet the new demand of the schools. The main characteristics are as follows:

1. 1 Low utilization rate of school assets

One of the reasons for the low utilization rate of assets is that the assets are managed by the department of application after the purchase. Certain departments do not ever consider the actual situation of their departments and optionally add assets, leading to idle, some just for the perfect assessment data.

\section{2 Non-standard of asset management}

The operation of the asset management system in some schools is not available. There is no explicit constraint between use department and management department. Accounts do not conform to the reality because of lack of supervision and the total assets are not clear.The asset management department can't grasp the first-hand data conveniently. The schools need to invest a lot of manpower and material resources into the inventory of assets, to prevent the loss of state-owned assets.

\subsection{Relative lag in the management mode}

In recent years, the nation advocates information campus construction. Vast majority of schools across the country are using computer information technology means in asset management. But the management pattern is relatively laggard, and cannot satisfy the needs of the development of the schools. Main features are as follows: some schools are still using the unconnected system, whose function is relatively single and cannot share the network resources. Barcode printing is of one dimensional code, where the storage of information is very small, only as a symbol for items, which cannot describe the detailed information of the item. Therefore, how to implement personalized management in fixed assets becomes the focus of the current work.

In this paper, smart phones are used as the user terminal equipment, providing the API interface function, supporting for $\mathrm{C} \#, \mathrm{C} / \mathrm{C}++$ programming language in Microsoft Visual.Net environment to develop applications. With a camera, the staff can take photos of the equipments, upload them to the storage system. Indoors, armed with WIFI, a reading and writing device can manage rapid convergence with the platform, realizing QR code scanning and reading of main assets. In the 
wireless network environment, the mobile terminal equipment scans QR code, reads the website information, logins in the school asset management website and realizes real-time query functions.

\section{Analysis on the functions of the asset management system}

According to operating procedures of college asset transaction, the system provides four main functions: first, registration of the assets means input of the main asset information and inventory arrangement. Second, general management of asset means daily management such as purchasing, evaluation, application and maintenance. Third, dynamic check of assets means college asset can be checked in real time in accordance with the number of assets, variety of assets. At the same time, assets of similar functions can be checked, offering reference to purchase. Asset check with mobile phones or other mobile terminals can realize real-time tracking of assets. Four, backstage data management, or data initialization means the recording of the user, using time, IP login and setting of user permissions.

Based on the above function analysis, the system can be divided into the six modules: system management, personal business, business management, routine management, system query, security module.

\section{Design of the asset management system}

\subsection{General description of the system}

This system adopts B/S structure, namely known as the three-tier architecture, including the data access layer, business logic layer and user show layer. Within this structure, users can reach the working interface only through the browser, which reduces the load of the client computer and eases the workload and upgrade of system maintenance and the overall cost of users.

The overall architecture of the system, based on LAN, can make the QR code label of assets in the system, use the existing equipment such as bar code printers to print the labels, and finally paste the labels to corresponding asset items, which can be operated by mobile devices such as mobile phones and tablets to realize the real-time query and management of the assets.

3.2 Overall frame design of the system

According to the description of the system functions above, the overall architecture of the system is designed as below in Figure 1.

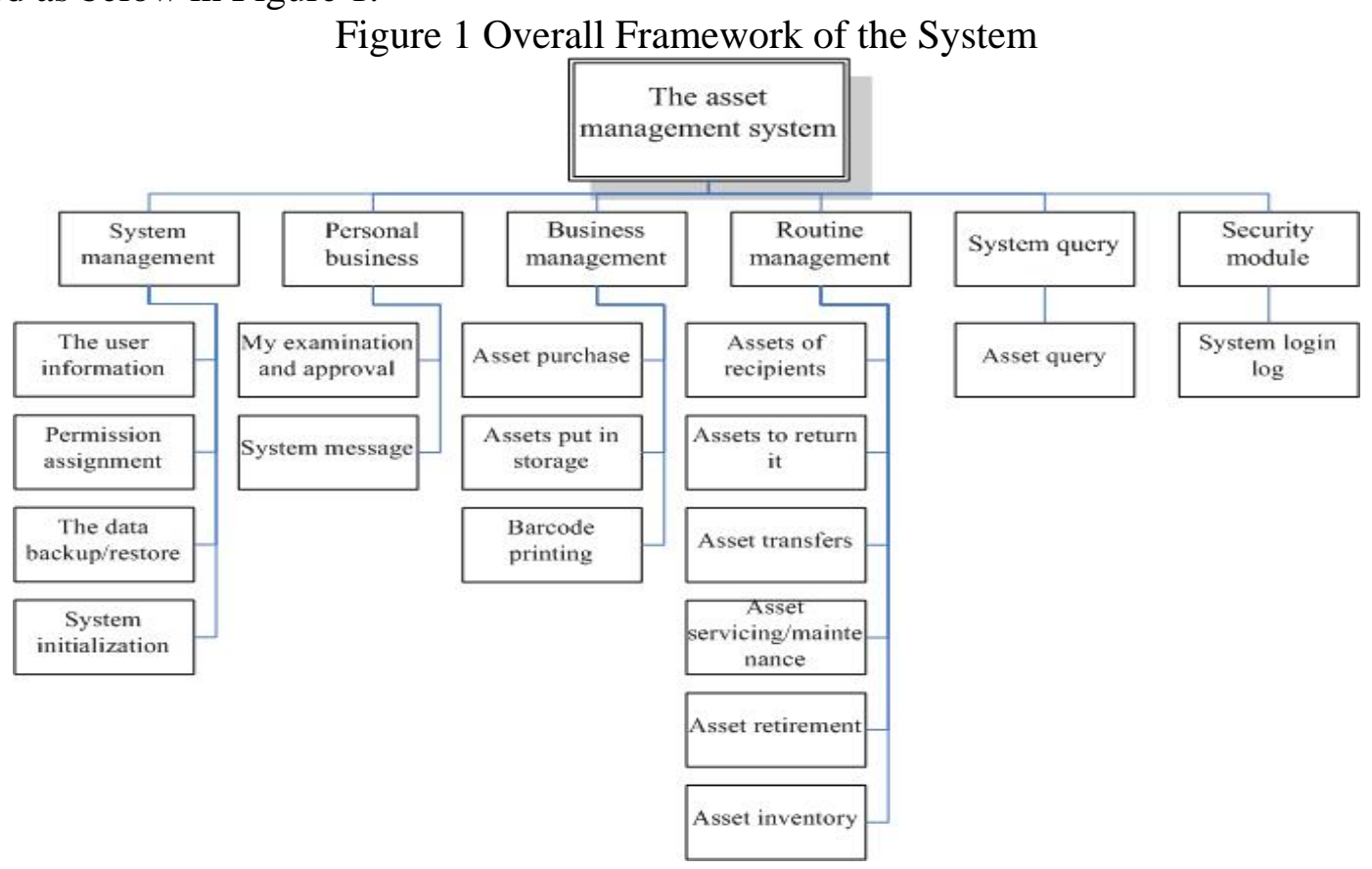

3.3 Some key technologies and the concrete implementation of the asset management system Implementation and the display effect of the login module is shown in Figure2: 
Figure 2 The User Login Interface

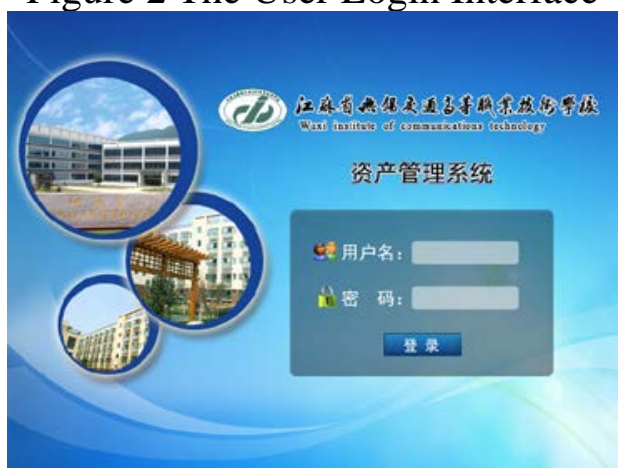

Figure 3 The Administrator Login Main Interface

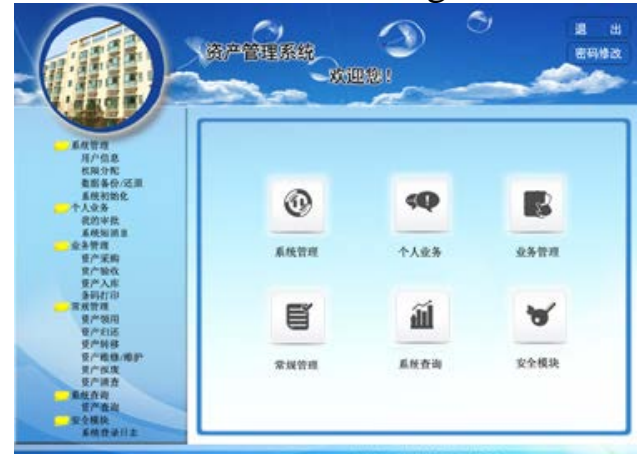

We can see from Figure 2, the login page requires the user to input user's name and password. When there is an error in the input, there will be a prompt like "wrong name or password! Please enter again!” When both the user's name and password are correct, a user can enter the system main interface, where the displays are different according to the users' right as shown in figure 9, which is the main login interface of the administrator.

Codes of implementation of specific login interface are as follows:

protected void submit_Click(object sender, EventArgs e)

\{

string strCmd = @"select count(*) from Admin_info where User_Name="" + this.admin.Text.Trim ()$+$ "' and PassWord="' + this.pwd.Text.Trim() + "'";// Set the query if (dbManager.CheckUser(strCmd))// Determine the user name and password are

correct \{

string sql = @"select * from Admin_info where User_Name="" + this.admin.Text.Trim() + "' and UserPassword="' + this.pwd.Text.Trim() + "'";// Get the user name and department information

DataSet memidDs = new DataSet();

memidDs = myclass.getDataSetBySQL(sql);

string userName $=$ memidDs.Tables[0].Rows[0].ItemArray[1].ToString();

string department $=$ memidDs.Tables[0].Rows[0].ItemArray[3].ToString();

Session["User_Name"]=userName;

// Add a user name in the Session

Session["Department"] = department; // Add department information in the

Session

string duty= DateTime.Now.ToString(); // Gets the current date

string ip = Request.ServerVariables["REMOTE_ADDR"]; // Get the client IP

string sqlAdd = "insert Enter_info

values('"+userName+"',"'+department+"',"'+duty+"',"'+ip+"')";// Add the statement

if (dbManager.ExecuteSql(sqlAdd))

\{ 


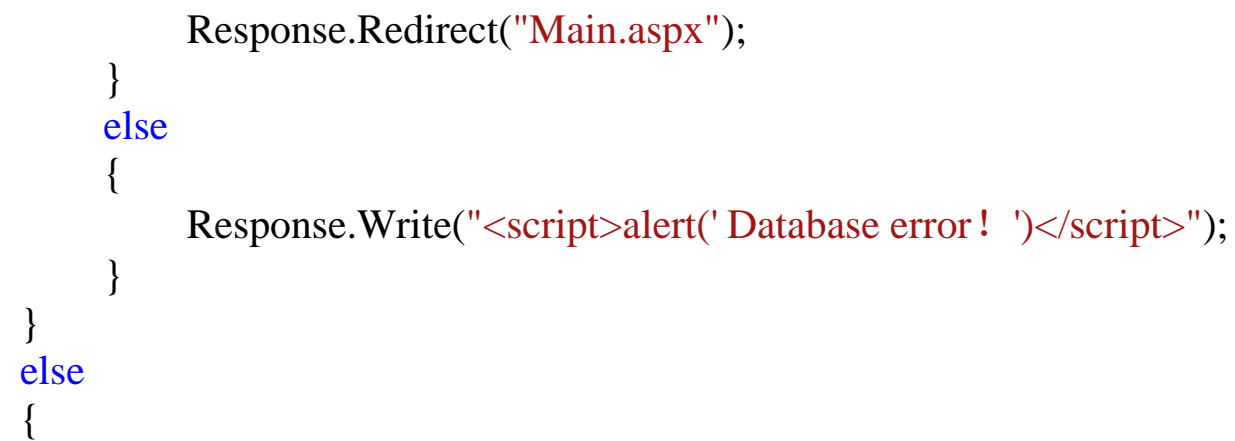

Response.Write("<script>alert(' Name or password you entered is wrong ! Please input again ')</script>");

\section{Conclusion}

The level of college management performance has been improved dramatically through the development and application of the asset management system. The main improvement was shown in four aspects: first, the work of asset management is more structured by promoting informationization and networking of fixed assets management. Second, because of the real-time check of the asset information, the effort of monitored control of asset is strengthened, the assets utilization is improved, and the cost of college operation is saved. Third, in the aspect of asset assessment and check, the input of manpower and material resources is reduced, and in the meantime, the related workload is simplified. Fourth, managing staff can take the real-time control and reasonable use of assets because of institutionalization, transparency, information of college asset management. The system is developed and designed with B/S structure, with key technologies as ASP.NET, QR code technology, Internet/Web database, in accordance with the actual situation of the networking and information management needs of assets in Wuxi Institute of Communication Technology, which saves manpower, material resources and time. Nevertheless, due to the complicated condition of college assets (huge variety, large quantity and large liquidity), the practical management work is quite complicated, the system can make great achievement in aspect of college asset management in online environment if the system is used with the popular technology of "radio frequency" together.

\section{Reference:}

[1] Ma Chun-yu. The university fixed asset management system based on Web way design. Digital Technology and Application, 2012,31-33(in Chinese)

[2] Wen Hui.On Fixed Assets Checking of the University. Experiment Science and Technology, 2012. 10(5):p. 169-173 (in Chinese)

[3] Wu Xiao-yang, Colleges and universities based on Internet of fixed assets management in the application of RFID technology. Public Communication of Science \& Technology, 2015.01,30-33(in Chinese)

[4] Zhang Zhen-feng, Zhou Wei. Study of universities fixed asset information management solutions based on RFID. Microcomputer \& Its Applications,2014,33（3）,12-15(in Chinese)

[5] Zuo Jia-xu. Management problem and countermeasure analysis of fixed assets in institutions of higher education. Communication of Finance and Accounting. 2012(05): 69-70(in Chinese)

[6] V. V. Kumar, R. S. D. Wahidabanu. Customer Relationship Management on J2EE and. NET using Business Intelligence (A Comparative Study on net and j2ee Platforms on various Parameters and Features). International Journal Of Data Mining And Emerging Technologies, 2012, 2(1):41-48. [7] Zhang Xiao-lin, Li Hui. Design and Implementation of Higher Education Fixed Assets Management System Based on J2EE. Computer Technology and Development,2012(in Chinese) 